\title{
Proposal of Blood Glucose Prediction Method Based on MHC Theory
}

\author{
Ryo Takeuchi a, ${ }^{*}, K_{\text {Kazuhiko Nagao }}{ }^{\mathrm{b}}$, Hiroyuki Miyamoto ${ }^{\mathrm{a}}$ \\ a Department of Human Intelligence Systems, Graduate School of Life Science and Systems Engineering, Kyushu \\ Institute of Technology, in Japan, 2-4 Hibikino, Wakamatsu-ku, Kitakyushu, Fukuoka 808-0196, Japan \\ bInformation Science and Technology Department, National Institute of Technology, Yuge College, in Japan, \\ 1000,Yuge Shimoyuge, Ochi Gun Kamijima, Ehime 794-2593,Japan \\ *Corresponding Author: takeuchi.ryo182@mail.kyutech.jp
}

\begin{abstract}
According to the WHO, 422 million adults worldwide have diabetes. Patients with diabetes should routinely measure and control their blood glucose levels. However, existing blood glucose meters collect blood using a needle, which causes problems such as pain and infection. A measuring instrument for solving this problem is called a non-invasive blood glucose meter, but there is no one that has been put into practical use at present. We are continuing research on non-invasive blood glucose measurement to reduce the burden on diabetic patients. As a result of previous studies, a simple non-invasive blood glucose meter and blood glucose management system were developed. At present, it aims at the improvement in the prediction accuracy of blood sugar level. In this paper, the result of examining the blood sugar level prediction technique is reported.
\end{abstract}

Keywords: blood glucose, non-invasive, MHC.

\section{Introduction}

Diabetes is one of the top 10 causes of death in the world. The World Health Organization (WHO) has reported that 422 million adults worldwide have diabetes [1]. Meanwhile, the number of diabetics in Japan in 2014 was 3166000, an increase of 466000 from a survey 3 years ago. In addition, as shown in Figure 1, the number of persons with strongly suspected diabetes has increased from 1997 years to the present [2], and the number of diabetics is expected to increase in the future. Treatment of patients with diabetes aims to prevent the development or exacerbation of the

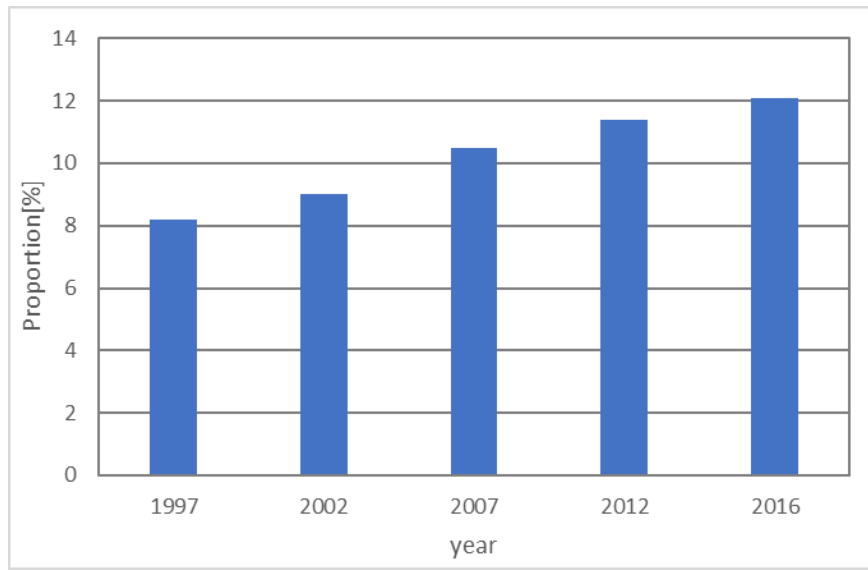

Fig.1. Trends in people suspected of being strongly susceptible to diabetes [2]

complications characteristic of diabetes and those that are more likely to occur with diabetes and to maintain a quality of life similar to that of healthy people [3]. In diabetes management, blood glucose levels must be continuously measured.

Currently, self-monitoring blood glucose meters that can measure blood glucose levels at home are commercially available. By using this, the blood glucose level can be confirmed. However, current blood glucose self-monitoring devices take a blood sample from a fingertip with a needle and measure it. Therefore, various problems have occurred [4]. First, because the measurement is performed using a needle, it is painful and the patient is stressed at each measurement. Needles and test strips are expensive because they are disposable and can cause infections when blood is drawn. In addition, continuous blood glucose monitoring in diabetes management may require several blood glucose measurements per day, depending on the severity of the disease, resulting in inflammation of the blood collection site. To solve these problems, minimally invasive blood glucose 
meters have been developed. For example, FreeStyle Libre, developed by Abbott Diabetes Care Inc. USA, still has a high false-positive rate for hypoglycemia [5]. Although it is minimally invasive, the use of a needle has not solved the problem of pain and infection. In order to completely solve these problems, there is a need for a measuring instrument that is inexpensive, does not require replacement of the needle or test paper for each measurement, can be easily measured at home, and does not cause any sanitary problems, and does not require blood collection. Such a measuring instrument is called a non-invasive blood glucose meter, and there is no practical one at present.

The importance of glycemic control in medical institutions as well as in patients with diabetes is drawing attention. In Berghe et al. 's study [6], controlling blood glucose to $80 \sim 110 \mathrm{mg} / \mathrm{dL}$ in patients with Intensive Care Units (ICU) improved mortality from $4.6 \%$ to $8.0 \%$. And, it was confirmed that the decrease in the complication was possible. In addition, the American Society for Intensive Care has stated that it is desirable to control blood glucose levels below $150 \mathrm{mg} / \mathrm{dL}$ as a treatment strategy for sepsis and associated shock [7]. Thus, awareness of the importance of glycemic control in ICUs has increased, and discussions have been held in related societies. In recent years, with the modernization of hospitals, there have been e-health and telemedicine using IOT, human care, and health services for monitoring patients [8-11]. At present, however, an appropriate blood glucose monitoring system does not exist, and blood glucose levels are measured by blood sampling every few hours in clinical practice. Therefore, a lot of work is required including the prevention of infectious diseases for blood collection. Therefore, the existence of a blood glucose meter and a management system that can measure blood glucose continuously and noninvasively can be said to have great medical benefits.

The theory of noninvasive blood glucose measurement has been studied for some time. Table 1 shows a comparison of noninvasive glucose monitoring [12] [13]. Previous studies have attempted to measure blood glucose using optical methods [14] or temperature methods [15]. In the case of the optical technique, the size is $20 \times 10 \times 5 \mathrm{~cm}$ without the power supply. On the other hand, it is possible to develop a small measuring instrument that can be mounted on a wearable terminal by a method using temperature. This method, called the metabolic heat formation (MHC) method, is based on a correlation between glucose levels in the body and the amount of heat released by the body [15].

This study aims to develop a non-invasive blood glucose meter and blood glucose management system that can be

Table 1. Comparison of noninvasive blood glucose measurement method [12][13]

\begin{tabular}{|c|c|c|c|}
\hline & $\begin{array}{c}\text { Optical } \\
\text { method }\end{array}$ & $\begin{array}{c}\text { MHC } \\
\text { technology }\end{array}$ & $\begin{array}{c}\text { Smart lens } \\
\text { (Google) }\end{array}$ \\
\hline $\begin{array}{c}\text { Invasiveness } \\
\text { object }\end{array}$ & Noninvasive & Noninvasive & Noninvasive \\
\hline $\begin{array}{c}\text { Measurement } \\
\text { accuracy }\end{array}$ & High & $\begin{array}{c}\text { Metabolic } \\
\text { fever }\end{array}$ & $\begin{array}{c}\text { Glucose } \\
\text { concentration } \\
\text { in tears }\end{array}$ \\
\hline Medical waste & None & None & Low \\
\hline $\begin{array}{c}\text { Productization } \\
\text { of prototype }\end{array}$ & $\begin{array}{c}\text { medical } \\
\text { equipment }\end{array}$ & Failure \\
\hline Size & $20 \times 10 \times 5 \mathrm{~cm}$ & Hand size & Contact lens \\
\hline
\end{tabular}

used in the home. As a result of previous studies, a simple non-invasive blood glucose meter and blood glucose control system were developed. [16] A prediction model was also examined to improve measurement accuracy [17]. In this paper, we report the results of a study on the prediction of blood glucose levels considering multiple parameters of the human body in consideration of individual differences in vital reactions. We also report a study of new parameters that were not previously used in MHC theory.

\section{Method}

In a previous study by Stephenie et al. [15], the appropriate sites for noninvasive glucose monitoring were the skin, forearm, wrist, earlobe, and fingertip. The parameters required for MHC technology are heat radiation and convection. Heat radiation can be measured by Stefan Boltzmann's law and is determined as follows.

$$
\begin{aligned}
\mathrm{hr}= & \rho \times \sigma \times\left(\mathrm{Ts}^{4}-\mathrm{To}^{4}\right) \\
& \mathrm{hr}\left(\mathrm{W} / \mathrm{m}^{2}\right): \text { Heat radiation } \\
& \rho: \text { Skin surface reflection coefficient } \\
& \sigma: \text { Stefan Boltzmann constant } \\
& \mathrm{Ts}\left({ }^{\circ} \mathrm{C}\right): \text { Measured surface's temperature } \\
& \mathrm{To}\left({ }^{\circ} \mathrm{C}\right): \text { Surrounding temperature }
\end{aligned}
$$

Thermal convection is obtained as follows.

$$
\begin{aligned}
\mathrm{hc}= & \mathrm{h} \times(\mathrm{Ts}-\mathrm{To}) \\
& \mathrm{hc}\left(\mathrm{W} / \mathrm{m}^{2}\right): \text { Heat convection } \\
& \mathrm{h}: \text { convection coefficient }
\end{aligned}
$$

The formula for calculating the blood glucose level was 
derived by performing a linear regression analysis on the basis of equations (1) and (2) and the blood glucose level measured by an existing blood glucose meter. As an example, the following shows the results of the derivation of the prediction equation. The data used in the linear regression analysis were blood glucose levels and finger tip temperatures recorded in 1 adult male at room temperature of $28^{\circ} \mathrm{C}$. The sample size was 8 . As a result, the blood glucose level was calculated as follows.

$$
\begin{aligned}
& \text { Blood glucose }= \\
& 193.17+\mathrm{hr} \times(-96.13)+\mathrm{hc} \times 121.9
\end{aligned}
$$

The MHC theory is based on a correlation between glucose levels in the body and the amount of heat released by the body. In a previous study by Stephonie et al. [15], the correlation between glucose concentration and the amount of heat released from the body was 0.925 .

\section{System Configuration}

The purpose of this system is to easily measure and control blood sugar level even in ordinary homes. The system configuration of this system is shown in Fig. 2. It is mainly divided into a non-invasive blood glucose meter for measuring blood glucose levels and a smartphone app for controlling blood glucose levels. These contents are omitted because they are explained in the previous study [16].

\section{Examination of prediction methods}

In this study, measurement experiments using a noninvasive blood glucose meter, accuracy evaluation, and a blood glucose level prediction model were investigated. The evaluation criteria used for the accuracy evaluation are described in Chapter 4.1. Chapter 4.2 and subsequent sections report on experiments and accuracy evaluation.

\subsection{Error Grid Analysis}

The Error Grid Analysis (EGA) method based on the International Organization for Standardization (ISO) standard was used for the accuracy evaluation in this study. The EGA method can be used to evaluate the clinical accuracy of blood glucose meters and to examine the clinical validity of glucose monitoring systems. In addition, true and predicted blood glucose levels can be represented as a scatter plot, and the reliability of the blood glucose meter can be

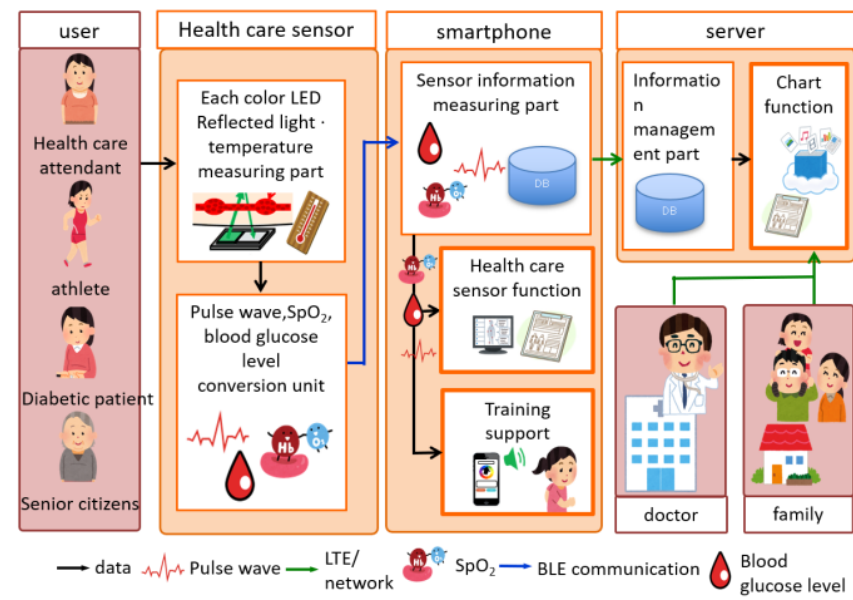

Fig.2. System Configuration

\begin{tabular}{|c|c|}
\hline Area & Description \\
\hline A & $\begin{array}{l}\text { The estimated blood glucose } \\
\text { level deviates about } \pm 20 \% \\
\text { from the actual value. }\end{array}$ \\
\hline B & $\begin{array}{l}\text { Self-monitoring device giving } \\
\text { predictive blood glucose level } \\
\text { degree results differ by more } \\
\text { than } 20 \% \text { from actual value }\end{array}$ \\
\hline $\mathrm{C}$ & $\begin{array}{c}\text { Poor results of self-monitoring } \\
\text { equipment }\end{array}$ \\
\hline $\mathrm{D}$ & $\begin{array}{l}\text { If detection fails, it is outside } \\
\text { the range of actual value ( } 70 \text { to } \\
\qquad 180 \mathrm{mg} / \mathrm{dL})\end{array}$ \\
\hline $\mathrm{E}$ & $\begin{array}{l}\text { False blood glucose level } \\
\text { causing serious problems in } \\
\text { diabetes management. }\end{array}$ \\
\hline
\end{tabular}

Table 2. Definition of EGA method

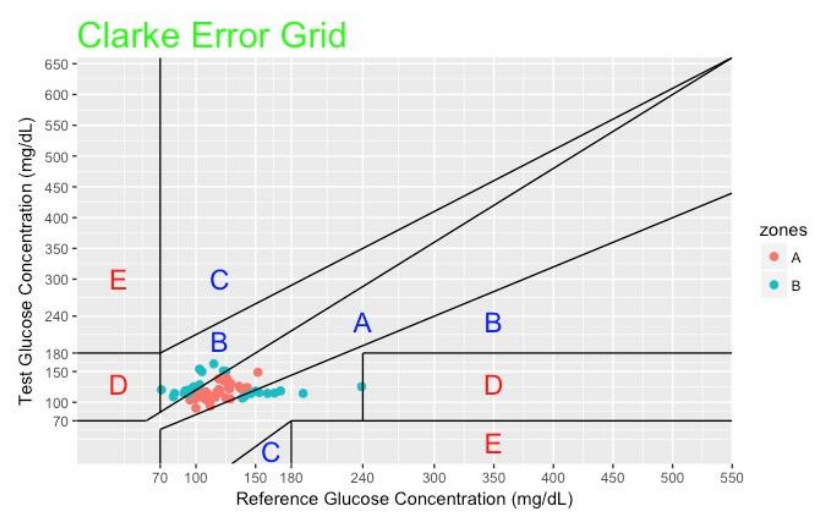

Fig.3. Linear Regression Analysis Results 
evaluated at five levels. Table 2 defines the evaluation. From Table 2, when data are plotted in regions $\mathrm{A}$ and $\mathrm{B}$, the precision is clinically acceptable. On the other hand, if data is plotted after region $\mathrm{C}$, it is inaccurate and clinically unacceptable.

\subsection{Linear regression analysis VS neural network}

We are comparing blood glucose prediction models as a result of previous studies [17]. Linear regression analysis and neural networks were used for comparison. The neural network is composed of three layers: an input layer, an intermediate layer, and an output layer. At this time, the prediction was performed using two parameters calculated from equations (1) and (2) and a blood glucose level measured by an existing blood glucose meter as an input. Half of the 136 datasets were used for learning and the other half for testing. The samples were taken between December 2017 and June 2018.

As an example, Fig. 3 shows the result of prediction using a linear regression analysis, and Fig. 4 shows the result of prediction using a neural network. Using linear regression analysis, values of $61.2 \%$ and $33.8 \%$ are plotted for Zone A and Zone B, respectively. In contrast, when the neural network was used, values of $70.5 \%$ and $29.5 \%$ were plotted for the A zone and the B zone, respectively. Thus, it was confirmed that the prediction accuracy could be improved by using neural networks.

\subsection{Influence of biological information}

Previous studies [17] have not considered differences in biological information. This chapter investigated the relationship between blood glucose levels and sex, age, weight, and height.

First, an experiment was conducted to investigate the relationship between the above parameters and blood glucose levels. In this experiment, measurement experiment was carried out in the health examination of Ehime Bank Co., Ltd. in November, 2018. The results showed that mean blood glucose levels were $96.38 \mathrm{mg} / \mathrm{dL}$ in women and $101.4 \mathrm{mg} / \mathrm{dL}$ in men, with mean blood glucose levels slightly higher in men. Table 3 shows the correlation coefficients between blood glucose levels and age, weight, and height. From these results, it was confirmed that age and weight were correlated with blood glucose levels, and that height was not. Based on these results, it is considered that accuracy can be improved by predicting blood glucose levels in consideration of age

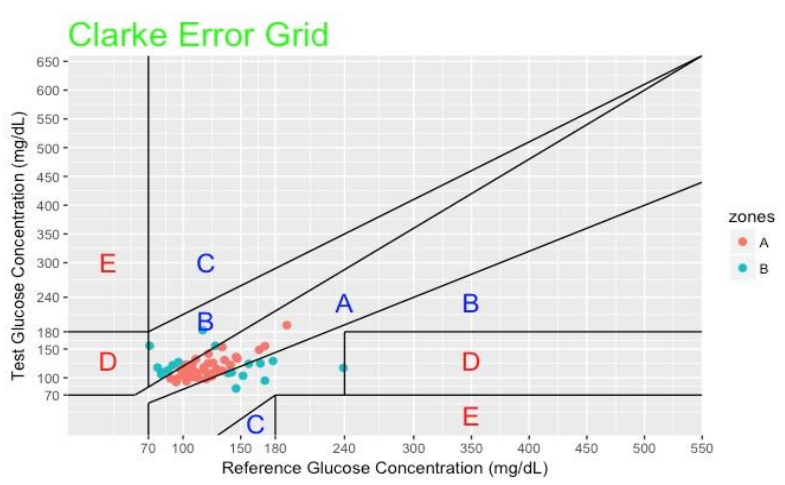

Fig.4. Prediction result by neural network

Table 3. Correlation coefficient between blood glucose level and each parameter

\begin{tabular}{|c|c|}
\hline Parameters & Correlation Coefficient \\
\hline Age & 0.412 \\
\hline Body weight & 0.214 \\
\hline Hight & -0.0161 \\
\hline
\end{tabular}

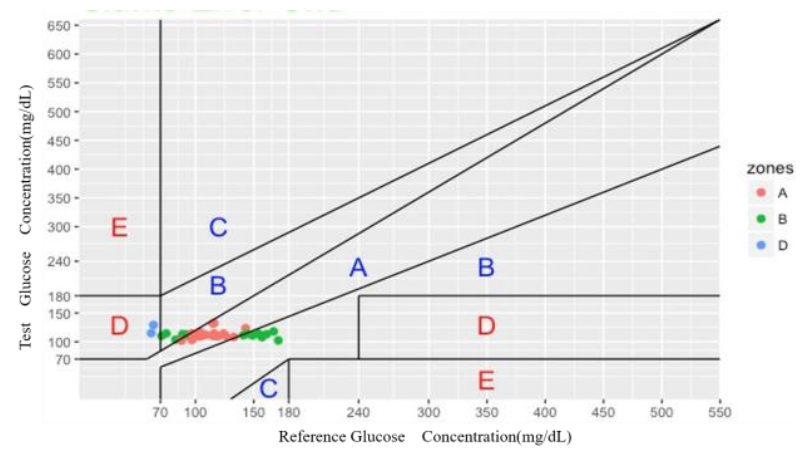

Fig.5. prediction Results (Parameter Type 2)

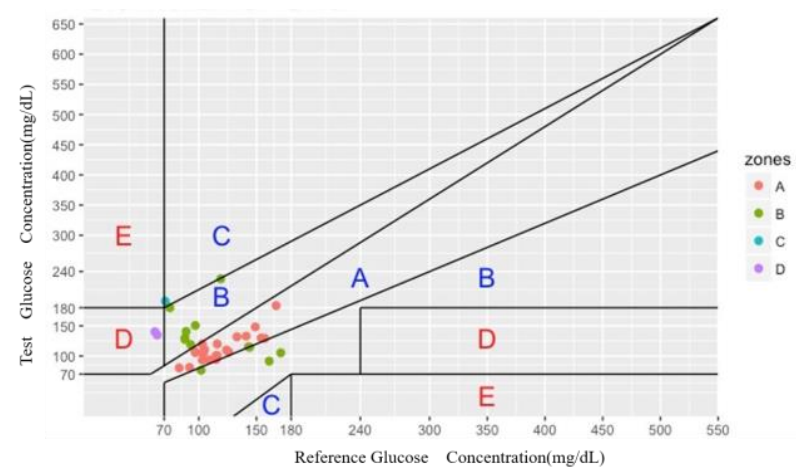

Fig.6. Prediction Results (Parameter Type 5) 
and body weight.

On the basis of these results, blood sugar level prediction considering sex, age and weight was carried out. The data used were 73 samples from the 32 Yumeshima Kaido Ikina Marathon held on March 3, 2019. For comparison, blood glucose levels were predicted using 2 parameters (Thermal radiation and thermal convection) and 5 parameters (Radiation, heat convection, gender, age, weight). The results are shown in Fig. 5 and 6. In Fig. 5, it can be said that the prediction results are biased and cannot be accurately predicted. In one way, in Fig. 6, values of $64.8 \%, 27.0 \%$, 2.7\%, and 5.4\% were plotted for Zone A, Zone B, Zone C, and Zone $\mathrm{D}$, respectively. Although slightly plotted in the $\mathrm{C}$ and $\mathrm{E}$ zones, most values were plotted in the $\mathrm{A}$ and $\mathrm{B}$ zones, and it was confirmed that the accuracy of blood glucose level prediction was improved by considering each parameter. The root mean squared error (RMSE) was $35.57 \mathrm{mg} / \mathrm{dl}$ when the prediction was made using 5 parameters.

\subsection{Predictions including pulse rate}

In this chapter, we discuss the prediction of blood glucose levels, including pulse waves, in addition to $\mathrm{MHC}$ techniques. The results of previous studies [15] and the previous chapters confirmed that $\mathrm{hr}$ and hc are important values for the prediction of blood glucose levels. However, there are other factors that change fingertip temperature besides the absorption of glucose in the body. Therefore, the present situation seems to be the limit for predicting the blood glucose level. We therefore considered adding new parameters in addition to MHC technology. The Kuragawa et al study [18] examined the prediction of fasting glucose by pulse waves. Takai et al. [19] reported a significant difference in pulse rate between healthy subjects and subjects with hyperglycemia. Thus, there may be a correlation between pulse rate and blood glucose level.

In this experiment, four parameters were obtained: preand postprandial blood glucose, thermal radiation, thermal convection, and pulse. Although it is desirable to monitor the progress of blood glucose levels after a meal until the blood glucose level falls, existing blood glucose meters use a needle, which limits the number of times they can be measured. Esposito et al. [20] reported that, in general, the peak postprandial hyperglycemia occurred $1 \mathrm{~h}$ after eating when glycemic control was normal. In the present study, 4 measurements were taken before, 30 minutes after, 60 minutes after and 3 hours after meals for several days. The sample number is 18 points from 1 subject.
Table 4. Comparison with prediction including pulse rate

\begin{tabular}{|c|c|c|}
\hline & $\mathrm{hr}, \mathrm{hc}$, & $\mathrm{hr}, \mathrm{hc}, \mathrm{HR}$ \\
\hline RMSE & 53.58 & 20.94 \\
\hline
\end{tabular}

Based on these data, two types of prediction were performed and compared: prediction using only heat radiation and heat convection, and prediction of blood sugar level using heat radiation, heat convection and heart rate. For comparison, cross-validation was performed and the model was evaluated using RMSE. Table 4 shows the comparison results. From Table 4, it was confirmed that the accuracy of blood glucose level prediction may be greatly improved by adding pulse.

\section{Conclusions}

In this study, we compared linear regression analysis and neural networks in a blood glucose prediction model. In addition, the accuracy of blood sugar level prediction was improved by considering sex, age, and weight, which were not considered in the previous study. More over, although this is only one example, we confirmed the possibility that the prediction accuracy of blood glucose level prediction including pulse could be greatly improved. In the future, the number of data will be increased and the accuracy will be evaluated using the EGA method.

\section{Acknowledgment}

We would like to thank Ehime Bank, Ltd., Himeginsoft Co., Ltd., and Angel, a social welfare corporation, for their participation in the 31 and 32 Ikina marathons, which participated in the measurement experiments in this study.

\section{References}

(1) World Health Organization: "GLOBAL REPORT ON DIABETES", October 2017

(2) Ministry of Health, Labour and Welfare: "Heisei 28 nen kokuminkenkou ' eiyoutyousakeltuka no gaiyou (in Japan)", 2017/9

(3) Masakazu Haneda, Mitsuhiko Noda, Hiroshi Noto, Daisuke Yabe, Yukihiro Fujita, Atsushi Goto, Tatsuya Kondo, Eiichi Araki: Japanese Clinical Practice Guideline for Diabetes 2016, Diabetology International(2018), 9:1-45.

(4) Taku Takeda, "Keltutou ziko sokutei no gaiyou" The Journal of the Japanese Society of Internal Medicine, Volume 98 Number4, pp761-767, 2009

(5) Talib, A.J.; Alkahtani, M.; Jiang, L.; Alghannam, F.; Brick, R.; Gomes, C.L.; Scully, M.O.; Sokolov, A.V.; 
Hemmer, P.R. Lanthanide ions doped in vanadium oxide for sensitive optical glucose detection. Opt. Mater. Express 2018, 8, 3277-3287.

(6) G. V. D. Berghe, P. Wouters, et al.: Intensive insulin therapy in critically ill patients, New England Journal of Medicine, 345, 19, 1359(2001)

(7) P.R. Dellinger, J.M. Carlet, et al.:Surviving Sepsis Campaign guidelines for management of severe sepsis and septic shock, Surviving Sepsis Campaign Management Guidelines Committee, 32, 3, 858(2004)

(8) Del'Aulnoit,A.H.;Boudet,S.;Génin,M.;Gautier,P.-

F.;Schiro,J.;del'Aulnoit,D.H.;Beuscart,R.Development of a smart mobile data module for fetal monitoring in EHealthcare. J. Med. Syst. 2018, 42, 83.

(9) Abdellatif, A.A.; Emam, A.; Chiasserini, C.-F.; Mohamed, A.; Jaoua, A.; Ward, R. Edge-based compression and classification for smart healthcare systems: Concept, implementation and evaluation. ExpertSyst. Appl. 2019, 117, 1-14.

(10) Ferlie, E.B.; Shortell, S.M. Improving the quality of health care in the United Kingdom and the United States: A framework for change. Milbank Q. 2001, 79, 281-315.

(11) Shen, H.; Ma, D.; Zhao, Y.; Sun, H.; Sun, S.; Ye, R.; Huang, L.; Lang, B.; Sun, Y. MIAPS: A web-based system for remotely accessing and presenting medical images. Comput. Methods Progr. Biomed. 2014, 113, $266-283$.

(12)"Saiketu ga huyou, hisinsyuu keltutouti sensa no zituyouka ni tyousen (in Japan)", National Institutes for Quantum and Radiological Science and Technology, https://www.qst.go.jp/site/press/1230.html , (reference 2019/11/28)

(13) Blum,Z.; Pankratov,D; Shleev,S.Powering electronic contact lenses: Currentachievements, challenges, and perspectives. Expert Rev. Ophthalmol. 2014, 9, 269273.

(14) M.C. Pande, A.K. Joshi: "Non-Invasive Blood Glucose Measurement", April 2015

(15) S. Y. H. Kit, :Non-Invasive Blood Glucose Measurement Using Temperature-based Approach, Universiti Teknologi Malaysia, 81310 UTM Johor Bahru, Johor, Malaysia

(16) Ryo Takeuchi, Atsuki Seo, Kazuhiko Nagao: "hisinsyuu keltutou sokuteiki no kaihatu oyobi seido tyousa (in Japan)", Information Processing Society of Japan, Forum on Information Technology 2018, No.CO-004, pp47, Fukuoka Institute of Technology, 2018/9

(17) Ryo Takeuchi, Kazuhiko nagao: “ MHC gizyutu wo motiita hisinsyuu keltutousokuteiki no kaihatu (in Japan), Information Processing Society of Japan, The 81 st National Convention of IPSJ, No.6ZG-08, pp665-666, Fukuoka University nanakuma campus,2019/3

(18) Esposito K, Ciotola M, Carleo D, Schisano B, Sardelli L, Di Tommaso D, Misso L, Saccomanno F, Ceriello A, Giugliano D(2008)Post-meal glucose peaks athome associate with carotid initima-media thickness in type 2 diabetes.JClin Endocrin Metab 93 : 1345-1350

(19) Takaji Takai, Ayako Matsuda, Koshi Saito, Kunihiro Yamamoto, Yoshikazu Sakamoto, Takeshi Kuzuya, Sho
Yoshida, and Meisei Ota : Variations in Heart Rate During Deep Breathing as an Early Index of Diabetic Autonomic Neuropathy, J.Japan Diab. Soc. 26(1):37 43, 1983

(20) Shintaro Kurasawa, Shouhei Koyama, Hiroaki Ishizawa, Keisaku Fujimoto and Shun Chino: Verification of NonInvasive Blood Glucose Measurement Method Based on Pulse Wave Signal Detected by FBG Sensor System, Sensors 2017,17,2702; doi:10.3390/s17122702 